\title{
Genome Expression to Targeted Therapy in Cancer Management
}

John Nemunaitis ${ }^{1-4^{*}}$

${ }^{1}$ Mary Crowley Cancer Research Centers, Dallas, Texas, USA

${ }^{2}$ Gradalis, Inc., Dallas, Texas, USA

${ }^{3}$ Texas Oncology, P.A., Dallas, Texas, USA

${ }^{4}$ Medical City Dallas Hospital, Dallas, Texas, USA

*Corresponding author: John Nemunaitis, 1700 Pacific, Suite 1100, Dallas, Texas 75201, USA, Tel: 214-658-1964; Fax: 214-658-1992; E-mail: jnemunaitis@marycrowley.org

Rec date: Apr 18, 2014, Acc date: May 21, 2014, Pub date: May 23, 2014

Copyright: (c) 2014 Nemunaitis J. This is an open-access article distributed under the terms of the Creative Commons Attribution License, which permits unrestricted use, distribution, and reproduction in any medium, provided the original author and source are credited.

\section{Short Communication}

The picture seems simple...determine connectivity of cancer survival to driver DNA mutations, confirm related expressed protein and design therapeutics (small molecule, antibody, RNAi) to destroy the cancer. But is it so simple? Patients and doctors across the country now demand molecular signal assessment as part of the routine work up of resected malignant tissue characterization. With relevant correlation to disease progression and survival, utilization of matching molecular signals (BRAF, c-KIT, BCR-ABL, EGFR, HER2, ALK) to targeted therapy is paying dividends. However signals identified above have "companion" therapeutics. What about the multiple of molecular signals that relate to cancer growth but have no direct target therapeutic? Patients are benefiting with less toxic effect to these matched signal defects and targeted therapy approaches BUT how well trained are we as clinicians to interpret the thousands of signals involving DNA, RNA, protein and protein post translational components? There are 25,000 DNA sequences, 25,000 RNA sequences, 11,000 protein signals (which are multiplied further by protein post translation modifications). As Ellis et al. [1] point out, biochemical analysis is that link of genotype to phenotype of cancer critical for the translational success of involving cancer genome assessment in medical decision making. Targeted therapeutics, a 'new wave' of cancer treatments, are directed against amplified genes and/or over expressed proteins and protein kinases in malignant cells. However the presence of function redundancy in a robust, predominantly scale-free network such as cancer buffers the effect of any single gene/target modification on the malignant process, with rare exception (for example, CML) [2-4]. Molecular targets with low connectivity within the cancer signaling network have limited functional impact, HOWEVER, highly connected targets allow for "attack vulnerability" [3-6].

In 2007 [7] we demonstrated that semi-quantitative proteomic and genomic profiling derived by comparing malignant and nonmalignant tissue from patients with progressive cancer can be analyzed in the context of global protein interaction networks to generate a prioritized list of potential protein and gene targets. A novel target affecting microtubule modulation, STMN1 [1]: our review) was identified. Subsequently animal studies in mice and biorelevant rats were performed to determine optimal dosing, toxicology, biodistribution and evidence of preclinical efficacy of a novel bishRNAi nanoplex technology specifically targeting STMN1 [8]. These studies were done to strategically meet FDA requirements for IND establishment (clinical trial). This Phase I trial has now been initiated (IND\#14938) to evaluate safety in cancer patients. We are assessing STMN1 expression and knockdown in the patients receiving bishRNAi STMN1 nanoplex. Whether bi-shRNAi STMN1 nanoplex becomes another FDA approved targeted therapeutic for cancer management or just another clinical trial test agent, we don't know. However as gene/protein signal assessment becomes an increasing part of the cancer patient management, consideration and utilization of molecular signal information to match treatment opportunity with verified or experimental targeted therapies is an attractive direction for medical management. Future opportunity also holds promise in learning new signals for which new targeted therapies can also be conceived and/or developed.

\section{References}

1. Ellis MJ, Gillette M, Carr SA, Paulovich AG, Smith RD, et al. (2013) Connecting genomic alterations to cancer biology with proteomics: the NCI Clinical Proteomic Tumor Analysis Consortium. Cancer Discov 3: 1108-1112.

2. Hanahan D, Weinberg RA (2000) The hallmarks of cancer. Cell 100: 57-70.

3. Carlson JM, Doyle J (2002) Complexity and robustness. Proc Natl Acad Sci U S A 99 Suppl 1: 2538-2545.

4. Stelling J, Sauer U, Szallasi Z, Doyle FJ 3rd, Doyle J (2004) Robustness of cellular functions. Cell 118: 675-685.

5. Albert R, Jeong H, Barabasi AL (2000) Error and attack tolerance of complex networks Nature 406: 378-382.

6. Hartwell LH, Szankasi P, Roberts CJ, Murray AW, Friend SH (1997) Integrating genetic approaches into the discovery of anticancer drugs. Science 278: 1064-1068.

7. Nemunaitis J, Senzer N, Khalil I, Shen Y, Kumar P, et al. (2007) Proof concept for clinical justification of network mapping for personalized cancer therapeutics. Cancer Gene Ther 14: 686-695.

8. Phadke AP, Jay CM, Wang Z, Chen S, Liu S, et al. (2011) In vivo safety and antitumor efficacy of bifunctional small hairpin RNAs specific for the human Stathmin 1 oncoprotein. DNA Cell Biol 30: 715-726. 